\title{
The Comparison of Hemilaminectomy and Laminoplasty Procedures in the Surgical Treatment of Cervical Spondylotic Myelopathy
}

\author{
Mustafa KARADEMIR ${ }^{1}$, Ahmet KUCUK², Halil ULUTABANCA², Ahmet SELCUKLU², Ahmet MENKU², \\ Bulent TUCER ${ }^{3}$
}

${ }^{1}$ Afyonkarahisar State Hospital, Department of Neurosurgery, Afyonkarahisar, Turkey

${ }^{2}$ Erciyes University, Faculty of Medicine, Department of Neurosurgery, Kayseri, Turkey

${ }^{3}$ Acıbadem Kayseri Hospital, Department of Neurosurgery, Kayseri, Turkey

\section{ABSTRACT}

AIM: To compare cervical hemilaminectomy with cervical laminoplasty to determine the prognostic significance of both methods in cervical spondylotic myelopathy (CSM). This study is first in the literature to compare the hemilaminectomy and laminoplasty procedures

MATERIAL and METHODS: A total of 42 patients who underwent surgery due to CSM and followed for at least 24 months were included in the study. Thirty-four out of 42 patients were males, while 8 were females; the mean age of the patients was 63.6 years (range 41-80). The visual analog scale (VAS) was used in the evaluation of postoperative axial neck pain. Factors known to affect prognosis of CSM such as patients' age, gender, duration of symptoms, pressure level, and T2-hyperintense appearance on magnetic resonance imaging (MRI) were evaluated. Patients were compared in terms of sagittal alignment of the vertebrae (instability), anterior-posterior diameter of the spinal canal, transsectional spinal canal area, axial neck pain, and recovery rate based on the preoperative and postoperative Japanase Orthopaedic Association (JOA) scores.

RESULTS: The recovery rate in patients who underwent hemilaminectomy was $60.8 \% \pm 18.8$, while in patients that underwent laminoplasty it was $52.8 \% \pm 11.9$. The comparison of both surgical techniques in terms of postoperative recovery rates did not show any significant difference between the techniques $(p>0.05)$.

CONCLUSION: There were no significant differences in terms of recovery rate, preoperative and postoperative canal diameter, preoperative and postoperative spinal canal area, and postoperative sagittal alignment $(p>0.05)$. The VAS evaluating axial neck pain was significantly lower in patients from the hemilaminectomy group compared to patients from the laminoplasty group.

KEYWORDS: Cervical spondylosis, Myelopathy, Hemilaminectomy, Laminoplasty

\section{INTRODUCTION}

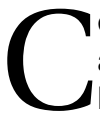
ervical spondylosis is a progressive process that is characterized by degeneration of intervertebral discs and loss of the liquid component together with decrease of the intervertebral disc height, resulting in spinal deformation. The degeneration that starts in the intervertebral disc insidi- ously spreads to surrounding bone and soft tissues $(11,23)$. The spinal canal narrows in a circular fashion due to development of a spondylotic bar in the front, uncovertebral joints in the front-side, facet joint hypertrophy, and ligamentum flavum hypertrophy on the rear-side $(12,29,37,38)$. Degenerative altering of one or more segments of the spinal cord and nerve 
roots with mechanical effects from the outside and vascular effects from the inside can lead to myelopathy. Cervical spondylotic myelopathy (CSM) is the major complication of cervical spondylosis. In developed countries, CSM is the most common spinal disease in patients over the age of 55 years. At the same time it is also the most common cause of non-traumatic spastic paraparesis and tetraparesis (3). The accompanying symptoms of CSM are progressive changes in sensation in the hands, decrease in dexterity, and development of stiffness and weakness in the legs $(3,21)$. The compression on the spinal cord or spinal vascular structures is responsible for the appearance of myelopathic symptoms. While the role of ischemia in the pathogenesis is controversial, small blood vessels in the spinal cord play an important role in the pathogenesis of compression and distortion. If the compression is prolonged, it may cause spinal cord degeneration, edema, cell loss, and the presence of necrosis-induced T2-hyperintense signal change known as snake eye appearance on magnetic resonance imaging (MRI) scans of the spinal cord $(3,23,48)$. Edwards and LaRocca have reported that the sagittal diameter of the spinal cord is correlated with myelopathy. Basically, the clinical manifestation that emerges as myelopathy, radiculopathy, or radiculomyelopthy becomes an important criterion in determining the surgical procedure to be applied $(7,38)$.

Fusion or non-fusion spinal cord decompression with anterior or posterior approach can be used as surgical treatment $(22,41)$. Methods of cervical posterior decompression include cervical laminectomy, laminectomy and posterior instrumentation, hemilaminectomy, laminoplasty, and arcocristectomy $(2,8,20,42)$. The object of the methods that use a posterior approach is to expand the canal and to eliminate the posterior compression if there is any. Evaluations of many factors such as cervical sagittal alignment (lordotic, straight, or kyphotic) and the localization of the compression (anterior or posterior) are important in the selection of the most appropriate approach in surgical treatment of CSM $(9,22,42)$. Anterior decompression and kyphosis correction is recommended for patients that have kyphosis, while in patients that have preserved lordosis and compression in the posterior the recommended approach is posterior approach $(37,43)$.

The aim of our study was to compare the cervical hemilaminectomy with cervical laminoplasty in patients with CSM and to determine their prognostic significance. This study is first in the literature to compare the hemilaminectomy and laminoplasty procedures.

\section{MATERIAL and METHODS}

\section{Operation Indications}

CSM patients who underwent surgery at the Department of Neurosurgery, Erciyes University and were followed-up for at least 24 months were prospectively included in the study. One surgeon had performed the hemilaminectomies and another one had performed laminoplasties. Among the 42 patients that were included in the study, $34(81 \%)$ were males and 8 (19\%) were females; the mean age of the patients was 63.6 years (range 41-80). While patients with clinical and radiologic findings indicative of CSM and whose preoperative Japanese Orthopaedic Association (JOA) scores were 17 or less were included in the study, individuals with early post-traumatic myelopathy, patients with only radiculopathy, and patients with disorders that could affect neurological outcomes such as amyotrophic lateral sclerosis (ALS), multiple sclerosis (MS), or other concomitant diseases were excluded from the study. CSM patients with an indication for surgical intervention underwent either cervical hemilaminectomy decompression $(n=21)$ or cervical laminoplasty $(n=21)$. All patients signed the informed consent form and understood that their computerized tomography and magnetic resonance image measurements would be used for a scientific research study. The follow-up examinations were evaluated by the surgeons who performed the surgical management themselves. The examination reports and radiological measurements were classified by each surgeon himself.

\section{Clinical Evaluation}

JOA scoring system modified by Benzel was used for preoperative and postoperative neurological assessment (4). The Visual Analogue Scale (VAS) was used for the evaluation of axial neck pain (46). The recovery rate used to evaluate the effectiveness of surgical intervention was calculated based on the formula defined by Hirabayashi et al. (15). A recovery rate of $>75 \%$ was considered as excellent, $50-75 \%$ was as good, $25-50 \%$ as insufficient, and $<25 \%$ as poor. Cervical spinal instability assessment was based on the criteria defined by the Cervical Spine Research Society in 2012 (6).

\section{Surgical Technique}

After the patient was anesthetized under general anesthesia, the patient's head was fixed in the prone position with slight flexion using a Mayfield head holder. After cleaning of the surgical area, the fluoroscopic control was done. By the hemilaminectomy procedure and via the midposterior skin incision, the spinous processes, laminae, and articular facets of the unilateral more severely symptomatic side were exposed by separating and retracting the paravertebral muscles from C3 to C7. The paravertebral muscles on the other side were kept intact. The exposed laminae were partially removed from the basal portion of the spinous processes. The operating table was rotated slightly with the approach side higher, to obtain a better visual field. Through these bony windows, internal plates of the laminae on the contralateral side were carefully drilled using a surgical air drill with a small-sized bit. We attempted to remove the internal lamina as far as the opposite edge of the dural sac while leaving in place the entire outer cortex and a small amount of spongiosa. At this stage, yellow ligaments are not removed to avoid dural-tube bulging. The lateral gutters were made in a line along the lamina facet border and were deepened to internal plates of the laminae to work as a hinge when remnants of the laminae were lifted up to widen the spinal canal. This procedure was performed at every level from C3 to C7. Finally, the yellow ligaments were carefully removed from the internal plate of the contralateral and the exposed-side laminae. By following these procedures, the spinal canal dorsolateral decompressive surgery were completed (Figure 1). A microscope was used for most cases 
that required drilling of the internal plates of the laminae on the contralateral side.

During the laminoplasty procedure; a midline cervical incision was taken down to the cervical fascia via a midline posterior approach. The cervical musculature was then reflected off of the involved cervical lamina. The level was then confirmed with a lateral plain radiograph or based on counting down from the occiput. Initially, a $4 \mathrm{~mm}$ laminectomy was created just medial to the level of the pedicles on the clinically more symptomatic side. A small Kerrison rongeur was used to remove the intervening ligaments and flavum. A $4 \mathrm{~mm}$ diamond burr was then used to thin out a 3 to $4 \mathrm{~mm}$ trough on the contralateral lamina, again just medial to the level of the pedicles. Care was taken to preserve the inner cortex on this side. The laminae were then lifted slowly to carefully create a greenstick fracture on the hinge side, expanding the spinal canal diameter. The cervical laminoplasty plate was then placed at each cervical level secured by a single 4-mm screw onto the lamina and two 4-mm screws at the level of the lateral masses (Figure 2). After all the cervical levels had a laminoplasty plate, the surgical wound was closed in layers.

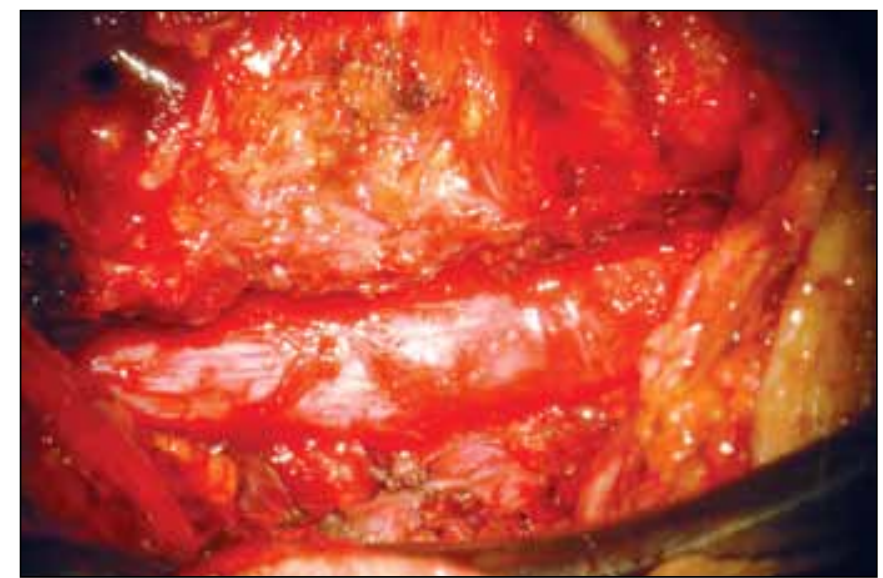

Figure 1: Cervical Hemilaminectomy: Peroperative photograph of cervical hemilaminectomy performed patient.

\section{Neuroradiological Evaluation}

The stability of the spine was evaluated using flexionextension dynamic radiographs that were taken after the $1^{\text {st }}$, $3^{\text {rd }}, 6^{\text {th }}$, and $12^{\text {th }}$ months and at 1 -year intervals afterwards $(5,6)$. The anterior-posterior diameter (A-P diameter) of the spinal canal was evaluated at C4-5 level on computed tomography (CT) images that were taken before and 3 month after the operation. It was defined as the region circumscribed by the posterior border of the vertebral body and the inner border of the lamina. The transsectional spinal canal area was measured on CT images at C4-5 level before and after the surgery, using a commercially available computer software program (the Erciyes University Faculty of Medicine PACS Radiological Imaging Software) (Figure 3). Using both surgical methods, postoperative $3^{\text {rd }}$ month, T2 sagittal and axial MRI were evaluated to view spinal cord compression (Figures $4,5)$. The postoperative paravertebral muscle atrophy was evaluated based on postoperative $3^{\text {rd }}$ month MRI T2 axial cross sections. Snake eye appearance was evaluated by T2 sagittal MR images (Figure 6).

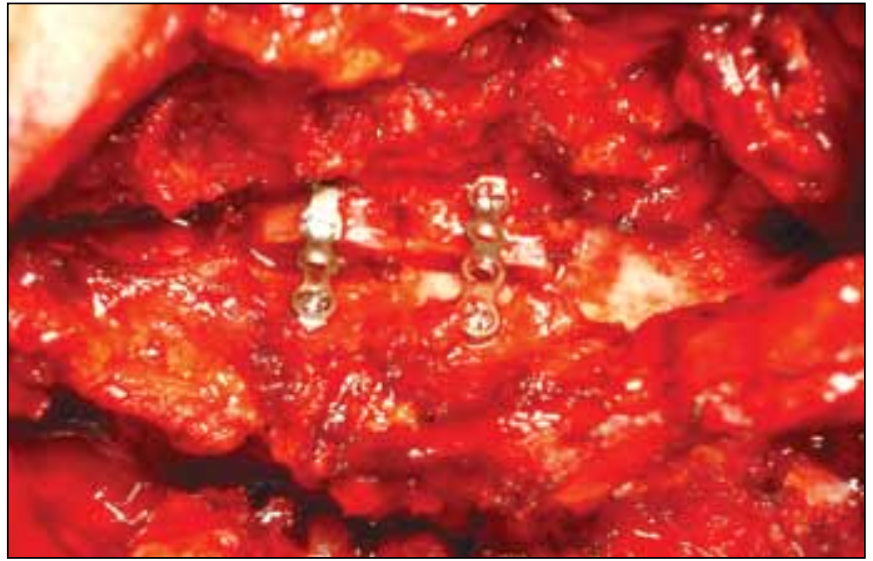

Figure 2: Cervical Laminoplasty: Peroperative photograph of cervical laminoplasty performed patient.
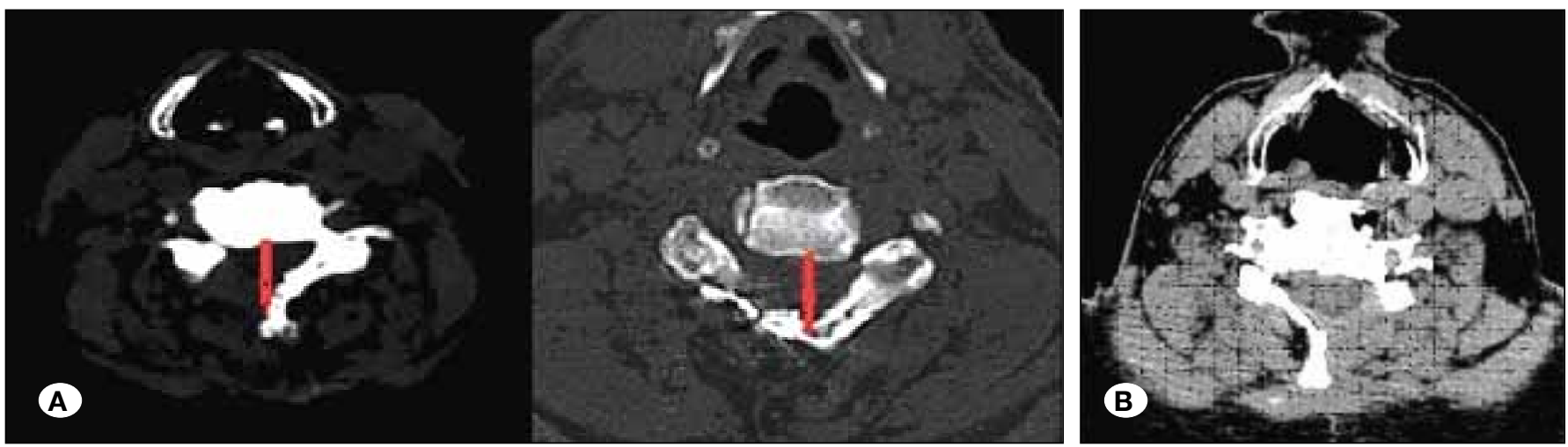

Figure 3: The CT images of anterior-posterior canal diameter and transsectional spinal cord area. After hemilaminectomy and laminoplasty procedures measurements; A) Anterio-posterior canal diameter, B) Transsectional spinal cord area. 


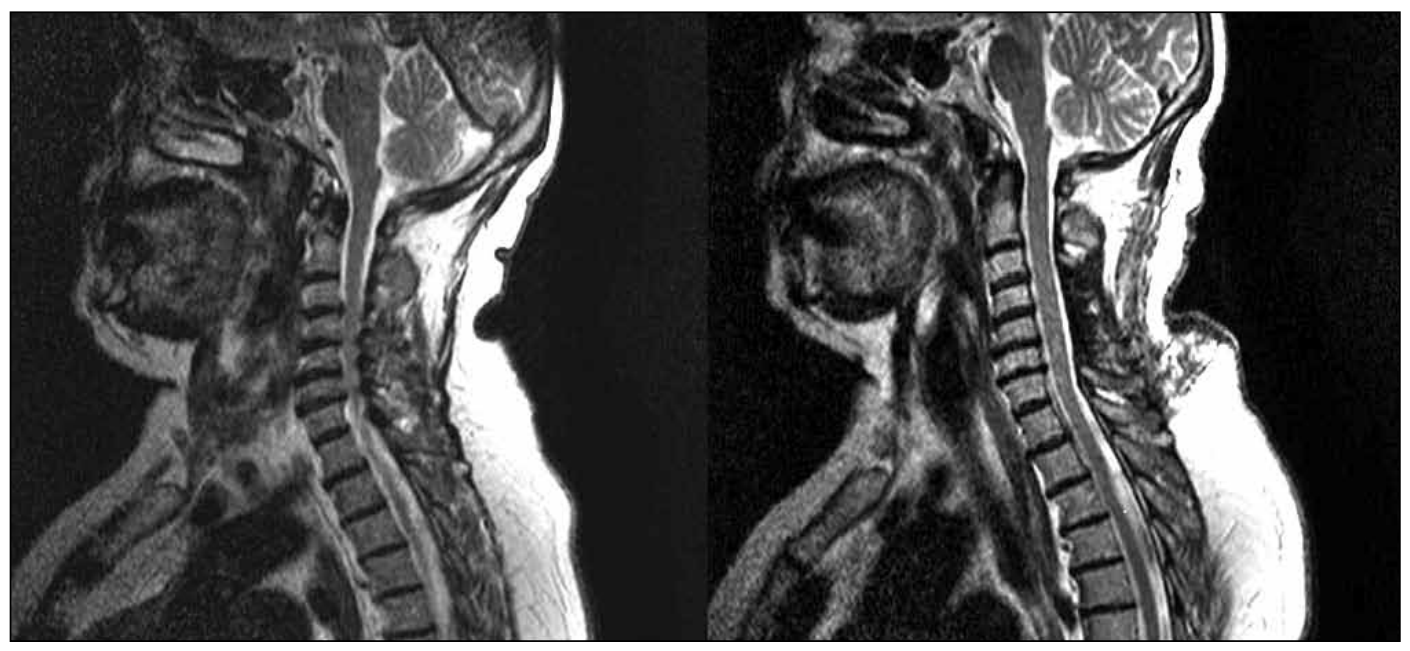

Figure 4:

The MR images of Hemilaminectomy performed patient. Preoperative (left) and 6-month postoperative (right) T2 sagittal MR images of a patient that underwent hemilaminectomy.

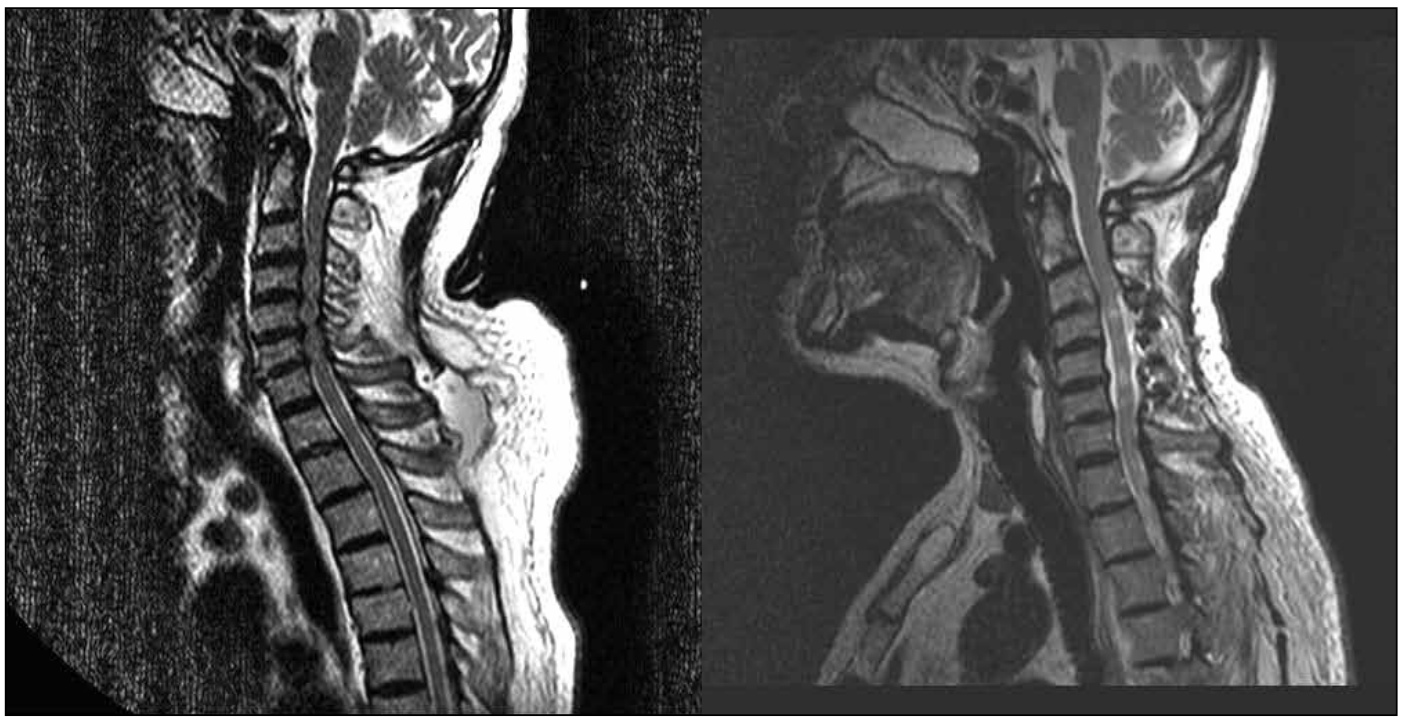

Figure 5: The MR images of Laminoplasty performed patient. Preoperative (left) and 6-month postoperative (right) T2 sagittal MR images of a patient that underwent laminoplasty.

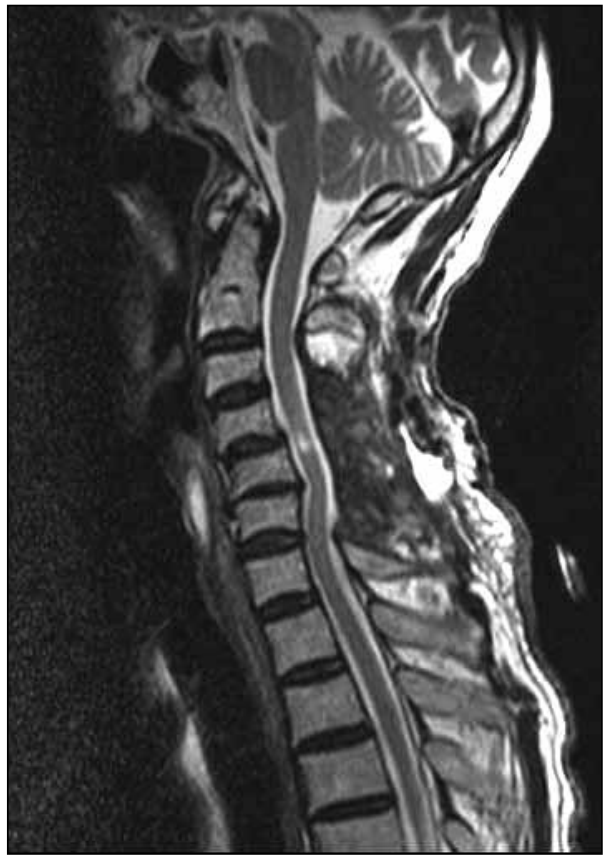

Figure 6: Snake eye appearance in T2 sagittal MR image.

\section{The Comparison of Hemilaminectomy and Laminoplasty Methods}

The patients that underwent hemilaminectomy and laminoplasty were compared in terms of gender, age (either above or under 50 years old), preoperative and postoperative neurological status (recovery rate based on the JOA score), the number of compression levels (first and second level or third level and above), duration of symptoms (less than or more than 1 year), cervical vertebrae alignment (instability), anterior-posterior canal diameter and spinal canal area on CT imaging, the presence or absence of signal intensity differences in T2-weighted sections in MRI, and postoperative axial pain scores. In addition, the effects of the two surgical techniques on prognosis of CSM were evaluated as well.

\section{Statistical Analyses}

The SPSS 15 and Sigmastat programs were used for the analyses. The Shapira-Wilk normality test was used to evaluate whether the data were normally distributed. The variables that were normally distributed and met parametric conditions were defined as $X \pm$ SD mean $(25 \%, 75 \%)$. The 
independent t-test and Mann-Whitney $U$ tests were used for comparison of the two independent groups. The categorical variables were compared with Chi-square test. A $p$ value less than or equal to 0.05 was considered as significant.

\section{RESULTS}

\section{Gender}

The study included 34 men (81\%) and 8 women (19\%) and an Male/Female ratio of $4.25 / 1$. There was no significant difference in terms of gender between patients that underwent hemilaminectomy and laminoplasty $(p>0.05)$. Male patients' mean preoperative JOA score was $12.79 \pm 2.6$ and the postoperative JOA score was $15.5 \pm 1.5$. Comparatively, females' preoperative JOA score was $11.0 \pm 2.6$, while the postoperative JOA score was $15.5 \pm 1.5$. Therefore, there was no significant difference between male and female patients in terms of preoperative and postoperative JOA scores in applied surgical methods ( $p>0.05)$.

\section{Age}

The mean age of the patients was $63.6 \pm 11.7$ years, and the age range was $41-80$. There were $8(19 \%)$ patients who were under the age of 50 , and 34 (81\%) patients who were over 50 years old. The preoperative JOA score of patients under the age of 50 was $14.6 \pm 0.90$, while the postoperative JOA score was $16.6 \pm 0.7$. Patients who were older than 50 had a preoperative JOA score of $11.9 \pm 2.7$ and a postoperative JOA score of $15.2 \pm 1.5$. In both age groups, there was a statistically significant increase in postoperative JOA scores $(p<0.05)$. In patients under the age of 50 , the increase in the postoperative
JOA score was higher than in patients over the age of 50 , and this difference was statistically significant (Table I) $(p<0.05)$.

\section{Recovery Rate}

The recovery rate in patients who underwent hemilaminectomy was $60.8 \% \pm 18.8$, while in patients that underwent laminoplasty it was $52.8 \pm 11.9 \%$. In addition, in 3 patients $(14 \%)$ that underwent hemilaminectomy, the recovery rate was excellent, in 15 patients $(72 \%)$ it was good, and in 3 patients $(14 \%)$ the results were unsatisfactory. Meanwhile, in 1 patient (5\%) that underwent laminoplasty the recovery was excellent, in 16 patients $(76 \%)$ it was good and in 4 patients $(19 \%)$ the recovery was insufficient (Table IV). The comparison of both surgical techniques in terms of postoperative recovery rates did not show any significant difference between the techniques (Table II) ( $p>0.05)$.

\section{Spinal canal anterior-posterior diameter}

The mean preoperative and postoperative anterior-posterior spinal canal diameter in patients that underwent hemilaminectomy was $9.7 \pm 1.1 \mathrm{~mm}$ and $14.1 \pm 0.9 \mathrm{~mm}$, respectively. In comparison, in patients that underwent laminoplasty, the mean preoperative and postoperative anterior-posterior spinal canal diameter was $9.5 \pm 0.5 \mathrm{~mm}$ and $13.6 \pm 0.4 \mathrm{~mm}$, respectively. In both groups, there was no statistically significant difference between preoperative anterior-posterior diameters $(p>0.05)$. However, in both groups the increase in postoperative anterior-posterior diameter was statistically significant $(p<0.05)$. The differences in increase in postoperative anterior-posterior diameter in patients that underwent hemilaminectomy and laminoplasty were not statistically significant ( $p>0.05)$ (Table II).

Table I: Correlation of Age and Preop and Postop JOA Scores

\begin{tabular}{|c|c|c|}
\hline Age & $\begin{array}{l}\text { Preop JOA X } \pm \text { S.D. } \\
\text { Mean }(25 \%, 75 \%)\end{array}$ & $\begin{array}{l}\text { Postop JOA X }+ \text { S.D. } \\
\text { Mean }(25 \%, 75 \%)\end{array}$ \\
\hline Over 50 years & $\begin{array}{c}11.9 \pm 2.70 \\
12.00(10.00,14.00)\end{array}$ & $\begin{array}{c}15.20 \pm 1.50 \\
16.00(14.00,16.00)\end{array}$ \\
\hline Under 50 years & $\begin{array}{c}14.60 \pm 0.90 \\
15.00(14.00,15.00)\end{array}$ & $\begin{array}{c}16.6 \pm 0.74 \\
16.50(16.00,17.00)\end{array}$ \\
\hline
\end{tabular}

Table II: Comparison of Hemilaminectomy and Laminoplasty Procedures

\begin{tabular}{|c|c|c|c|c|c|}
\hline $\begin{array}{l}\text { Surgical } \\
\text { Method }\end{array}$ & $\begin{array}{c}\text { Pre-op } \\
\text { A-P diameter } \\
\text { X } \pm \text { S.D. } \\
\text { Mean }(25 \%, 75 \%)\end{array}$ & $\begin{array}{c}\text { Post-op } \\
\text { A-P diameter } \\
\text { X } \pm \text { S.D } \\
\text { Mean }(25 \%, 75 \%)\end{array}$ & $\begin{array}{c}\text { Pre-op } \\
\text { A-P canal } \\
\text { X } \pm \text { S.SD } \\
\text { Mean }(25 \%, 75 \%)\end{array}$ & 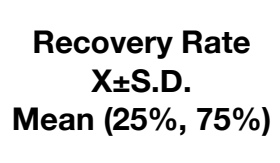 & $\begin{array}{c}\text { Post-op } \\
\text { Axial Pain } \\
\text { (VAS) X+S.D. } \\
\text { Mean (25\%, 75\%) }\end{array}$ \\
\hline Hemilaminectomy & $\begin{array}{c}9.7 \pm 1.1 \mathrm{~mm} \\
9.5(9.2,10.5)\end{array}$ & $\begin{array}{c}14.1 \pm 0.9 \mathrm{~mm} \\
14.1(13.3,14.9)\end{array}$ & $\begin{array}{c}132.0 \pm 10.3 \mathrm{~mm}^{2} \\
132.0(115.0,152.0)\end{array}$ & $\begin{array}{c}\% 60.8 \pm 18.8 \\
62.0(50.0,69.0)\end{array}$ & $\begin{array}{c}4.4 \pm 0.9 \\
4.0(4.0,5.0) \\
\end{array}$ \\
\hline$p$ & 0.677 & 0.147 & 0.235 & 0.108 & $<0.001$ \\
\hline
\end{tabular}




\section{Spinal canal area}

The preoperative mean spinal canal area in patients that underwent hemilaminectomy was $132.0 \pm 10.3 \mathrm{~mm}^{2}$ and the postoperative mean spinal canal area was $161.0 \pm 10.8 \mathrm{~mm}^{2}$. In patients that underwent laminoplasty the preoperative and postoperative mean spinal canal areas were 128.6 \pm 8.1 $\mathrm{mm}^{2}, 158.0 \pm 9.2 \mathrm{~mm}^{2}$, respectively. There was no significant difference between patients that underwent hemilaminectomy and laminoplasty in terms of preoperative mean spinal canal area $(p>0.05)$. The increase in the postoperative spinal canal area values was significant in patients that underwent both procedures $(p<0.05)$. However, there was no significant difference between the patients that underwent hemilaminectomy and laminoplasty in terms of postoperative spinal canal area (Table II), ( $p>0.05)$.

\section{Sagittal alignment and instability}

In the preoperative period, 19 patients (45\%) had lordotic, 19 patients $(45 \%)$ had straight, and 4 patients (10\%) had kyphotic sagittal alignment. Six of the patients that underwent hemilaminectomy had lordotic alignment, 2 had kyphotic and 13 had straight sagittal alignment. Comparatively, 13 of patients that underwent laminoplasty had lordotic, 2 had kyphotic and 6 had straight sagittal alignment. The difference between preoperative sagittal alignments in both groups was not significant $(p>0.05)$. None of the patients had instability in the preoperative period and their sagittal alignments did not change in the postoperative follow-up by each other different surgical methods..

\section{Symptom duration}

The patients' mean duration of symptoms was 15.2 \pm 10.1 months. There were 24 patients $(57 \%)$ whose symptom duration was under one year and 18 patients (43\%) whose symptoms had lasted for more than one year (Table III). The preoperative mean JOA scores of patients who had symptoms for less than one year was $12.3 \pm 2.8$, while their postoperative mean JOA score was $15.7 \pm 1.42$. In contrast, in patients who had symptoms for more than one year, the preoperative and postoperative mean JOA scores were $12.5 \pm 2.5$ and $15.2 \pm 1.6$, respectively. In both groups there was a statistically significant increase in postoperative JOA scores $(p<0.05)$. When patients who had symptoms for less than one year and patients who had them for more than one year were compared, there was no significant difference in terms of postoperative JOA scores $(p>0.05)$. Among the patients that underwent hemilaminectomy, 12 patients $(57.1 \%)$ had symptom duration of less than one year and 9 patients (42.9\%) had symptom duration longer than one year. Twelve of the patients that underwent laminoplasty $(57.1 \%)$ had symptoms for less than one year, while 9 (42.9\%) had symptoms for more than one year. When the postoperative JOA scores were compared there was no significant difference between applied surgical methods in terms of in the duration of symptoms (Table III) ( $p>0.05)$.

\section{Compression levels}

Thirteen patients had involved disc compression levels of 1 or 2 and 29 patients had compression levels of 3 or higher. In patients whose compression level was 1 or 2 , the mean preoperative and postoperative JOA scores were 13.3 \pm 2.0 and $16.0 \pm 1.2$, respectively. In patients with compression levels of 3 or higher the mean preoperative and postoperative JOA scores were $12.0 \pm 2.9$ and $15.3 \pm 1.6$. There was no statistically significant difference between the groups in terms of preoperative JOA scores ( $p>0.05$ ). However, in both groups there was a statistically significant increase in postoperative JOA scores $(p<0.05)$. With both surgical methods, there was no significant difference in terms of postoperative JOA scores between the patients with compression levels of 1 or 2 and patients with compression level of 3 or higher (Table IV), (p>0.05).

\section{The change in the MRI T2-hyperintense signal intensity (Snake eye appearance)}

Eleven patients who underwent hemilaminectomy had hyperintense appearance in MRI T2 sections in the spinal cord, while in 10 patients there was no hyperintense change. In 12 patients that underwent laminoplasty there was a T2 hyperintense appearance in the spinal cord sections, while in 9 patients there was no hyperintense change. In both groups, there was no significant difference between the two groups in terms of observance of preoperative MRI T2-hyperintense appearance $(p>0.05)$. In the hemilaminectomy group in patients that had hyperintense appearance on the MRI-T2 sections, the postoperative recovery rate was $58.00 \pm 16.85 \%$, while in patients that did not have hyperintense appearance the recovery rate was $64.00 \pm 21.23 \% \quad(p>0.05)$. In the laminoplasty group the postoperative recovery rate of patients who had hyperintense appearance was $50.3 \pm 11.58 \%$, while in patients that did not have hyperintense appearance the recovery rate was $55.5 \pm 12.49 \%$ ( $p>0.05)$. In both groups there was no significant difference between the patients that had hyperintense appearance in the MRI T2 sections and the ones that did not have the hyperintense appearance in terms of recovery rates (Table $\mathrm{V})(\mathrm{p}>0.05)$.

\section{Axial neck pain}

In patients that underwent hemilaminectomy, the mean postoperative VAS value for axial neck pain one year after the surgery was $4.4 \pm 0.9$. In patients that underwent laminoplasty, the mean VAS score for axial neck pain one year after the surgery was $5.8 \pm 0.7$. When the surgical methods were evaluated based on the postoperative axial neck pain, the patients who underwent hemilaminectomy had significantly less axial neck pain compared to the ones that underwent laminoplasty (Table II), $(p<0.001)$.

\section{Paravertebral muscle atrophy}

Six months after the hemilaminectomy and laminoplasty procedures, the paravertebral muscles were evaluated by using MRI T2 axial section images. Bilateral paravertebral muscle atrophy was observed in laminoplasty patients. On the other hand, in patients that underwent hemilaminectomy paravertebral muscle atrophy was observed at areas on the approach side. In those patients, the paravertebral muscle cross-sectional area on the approach side was 1594.1 1227.1 
$\mathrm{mm}^{2}$ and the contralateral area was $1948.8 \pm 177.5 \mathrm{~mm}^{2}$. In addition, we compared postoperative paravertebral muscle volumes in areas where the muscles were separated and retracted, with contralateral areas in patients that underwent hemilaminectomy and found significant differences between them $(p<0.001)$.

When the surgical techniques were compared with each other, there was no statistically significant difference in terms of postoperative JOA score and recovery rates ( $p>0.05)$. However, when we evaluated surgical approaches separately, there was a statistically significant increase in postoperative JOA scores in both surgical approaches $(p<0.05)$. The mean recovery rates in general and in both groups varied from good to excellent $(75-100 \%)$. The observance of hyperintense signal changes in $\mathrm{MRI}$, the duration of symptoms, and gender did not have any effects on recovery rates in both groups. Furthermore, the increase in postoperative JOA scores was higher in patients under the age of 50 compared to the patients over the age of 50 . The VAS scores for postoperative axial neck pain one year after the surgery was significantly lower in hemilaminectomy patients compared to patients that underwent laminoplasty $(p<0.05)$. In the postoperative period, in patients who underwent hemilaminectomy the paravertebral muscle atrophy was observed in areas where muscles were stripped, while in laminoplasty patients it was observed bilaterally.

\section{DISCUSSION}

Some initiatives during surgery are thought to be important factors in the preservation of cervical structures in the postoperative period. The preservation of the area where erector spinae muscles adhere to $\mathrm{C} 2$ and preservation of the integrity of the nuchal ligaments are also important in flexion deformity $(28,39)$. Chronic neck pain, kyphosis, neurological deterioration associated with postlaminectomy membrane in the dorsal dura, and the formation of scar tissue are among serious complications that could be encountered after laminectomy. Posterior instrumentation can be applied in order to prevent kyphotic deformity (31). Over the years, laminoplasty procedures have become alternatives for laminectomy and anterior multilevel decompressive methods. In 1968 Krita

Table III: Preoperative and Postoperative JOA Scores Based on the Duration of Symptoms

\begin{tabular}{lcc}
\hline Symptom Duration & $\begin{array}{c}\text { Preoperative JOA X } \pm \text { S.D. } \\
\text { Mean (25\%, 75\%) }\end{array}$ & $\begin{array}{c}\text { Postoperative JOA X } \pm \text { S.D. } \\
\text { Mean (25\%, 75\%) }\end{array}$ \\
\hline Less than one year & $12.3 \pm 2.8$ & $15.7 \pm 1.4$ \\
\hline More than one year & $13.5(10.0,15.0)$ & $16.0(15.0,17.0)$ \\
\hline $\mathbf{p}$ & $12.5 \pm 2.5$ & $15.2 \pm 1.6$ \\
\hline
\end{tabular}

Table IV: Correlation of Spinal Cord Compression Levels and Preoperative and Postoperative JOA Scores

\begin{tabular}{|c|c|c|}
\hline $\begin{array}{l}1 \text { or } 2 \text { levels } \\
\text { Spinal cord compression }\end{array}$ & $\begin{array}{c}13.30 \pm 2.09 \\
14.00(12.75,15.00)\end{array}$ & $\begin{array}{c}16.0 \pm 1.22 \\
16.00(15.75,17.00)\end{array}$ \\
\hline $\begin{array}{l}3 \text { levels ore more } \\
\text { Spinal cord compression }\end{array}$ & $\begin{array}{c}12.06 \pm 2.91 \\
12.00(10.00,15.00)\end{array}$ & $\begin{array}{c}15.34 \pm 1.63 \\
16.00(14.00,17.00)\end{array}$ \\
\hline
\end{tabular}

Table V: The Snake-Eye Appearance in MRI and Postoperative Recovery Rate by Two Different Surgical Methods

\begin{tabular}{|c|c|c|c|}
\hline Hemilaminectomy & $\begin{array}{c}58.0 \pm 16.8 \% \\
66.0(50.0,66.0)\end{array}$ & $\begin{array}{c}64.0 \pm 21.2 \% \\
58.5(48.5,81.2)\end{array}$ & 0.83 \\
\hline Laminoplasty & $\begin{array}{c}50.8 \pm 11.5 \% \\
50.0(40.2,60.0)\end{array}$ & $\begin{array}{c}55.5 \pm 12.4 \% \\
50.0(50.0,66.0)\end{array}$ & 0.46 \\
\hline
\end{tabular}


described the use of laminoplasty in cervical myelopathy which despite the introduction of wide variety of treatment methods including open door laminoplasty, has been among the most widely used methods $(17,24)$. In 2013 Lao et al. determined that both cervical laminectomy and laminoplasty methods were suitable for treatment of CSM and that preference should be determined based on clinical and radiological evaluation (26). In the prospective study conducted by Suk et al., they reported that postlaminectomy membrane was not observed after laminoplasty (42). One of the most important issues to be considered after the posterior cervical decompression surgery is preservation of lordotic cervical structure and prevention of kyphosis. Development of kyphotic deformity after surgery significantly affects neurological recovery (46). However, in both animal experiments and clinical trials, formation of kyphosis following the laminoplasty procedure has been reported to be less frequent compared to kyphosis formations after laminectomy $(10,45)$. Suk et al. reported that the rate of kyphosis formation after laminoplasty was $10.6 \%$ (42). Few other studies have compared laminoplasty and laminectomy and concluded that laminoplasty was more advantageous due to better preservation of muscle structure and less frequent kyphosis and instability $(10,13)$.

The formation of a post-laminectomy membrane or scar tissue leads to restenosis after laminectomy. In order to prevent these drawbacks, the cervical laminectomy method has been modernized and the cervical hemilaminectomy decompression method has been implemented to preserve the sagittal alignment and stabilization $(14,33)$. Unilateral cervical hemilaminectomy decompression is a surgical procedure developed to reduce complications of current practices used in the treatment of CSM. In the hemilaminectomy methods, in order to prevent cervical sagittal alignment, paravertebral muscles are stripped unilaterally and muscles in the contralateral area are protected to prevent postoperative instability. In addition, preservation of interspinous and supraspinous ligaments are intended to contribute to the stabilization (14). Moreover, the use of the cervical hemilaminectomy decompression method aims to reduce the operation cost and duration by not using instrumentation and fusion, decrease the perioperative blood loss by stripping the paravertebral muscles unilaterally, prevent paravertebral muscle atrophy, and ease the postoperative axial symptoms $(14,25,33)$.

Among the 42 patients evaluated in our study, 21 patients underwent cervical hemilaminectomy, and 21 patients underwent cervical laminoplasty. Both surgical methods were compared to each other and the significance of hemilaminectomy and laminoplasty in the prognosis of CSM was determined.

Satomi et al. reported a $60.7 \%$ recovery rate in patients that underwent the open door laminoplasty (40). In a similar study, Matsuyama et al. reported a $50.8 \%$ recovery rate in patients that also underwent open door laminoplasty (30). Likewise, Hidai et al. evaluated hemilaminectomy patients and reported a recovery rate of $56.4 \%$ (14). Consistent with the literature, in our study we determined that the recovery rate after hemilaminectomy was $60.85 \% \pm 18.82$, while the recovery rate after laminoplasty was $52.85 \pm 11.91 \%$. There was no significant difference between hemilaminectomy and laminoplasty in terms of recovery rates.

Lee and Manzano examined the effect of gender on the prognosis of CSM, and similar to our study, they did not detect any significant relationship (27). Moreover, they also reported that patients younger than 60 years old showed better neurological improvement (27). Similarly, Yamazaki et al. determined that the mean postoperative JOA scores were significantly lower in patients with advanced age compared to younger patients (47). In our study, the age of 50, which is the time of accelerated degeneration, was considered as a reference and patients were classified as under the age of 50 and above the age of 50 . In patients that underwent hemilaminectomy and laminoplasty the postoperative neurologic improvement was significantly lower in patients over the age of 50 .

In the study by Lee and Manzano of 13 patients whose symptoms lasted for more than 18 months, only 10 patients (77\%) had improved walking, whereas 11 out of 12 patients (92\%) whose symptoms lasted less than 18 months had postoperative improved walking (27). Yamazaki et al. reported that the duration of symptoms only affects the outcome in patients with advanced age (47). In contrast, Naderi et al. did not find any link between duration of symptoms and recovery (36). In our study, we classified the duration of symptoms as less than one year and more than one year. We did not find any significant relationship between duration of symptoms and postoperative neurologic improvement.

Edwards and La Rocca reported the correlation between sagittal diameter of the spinal canal and myelopathy (7). Accordingly, while myelopathy is not observed in sagittal diameter greater than $17 \mathrm{~mm}$, spondylotic findings are revealed in sagittal diameter of $13-17 \mathrm{~mm}$. Yamazaki et al. found that canal diameter is effective in prognosis in younger age groups, but not all age groups have similar effects (47). Lee and Manzaro calculated the ratio of front-rear length of the spinal canal to the front-rear length of the vertebral body (27). They found that this rate was significantly increased in the postoperative period. In a study conducted by Hidai et al., a significant increase in the anterior-posterior diameter of the spinal canal was detected after the hemilaminectomy (14). Similarly, Hirabayashi et al. observed significant increases in the anterior-posterior diameter of the spinal canal in patients that underwent open door laminoplasty (16). Naderi et al. reported that they did not observe any significant relationship between the canal diameter and preoperative-postoperative neurological status and recovery rates (36). In our study, we detected a significant increase in postoperative anteriorposterior diameter of the spinal canal in patients that underwent hemilaminectomy and laminoplasty. However, when both surgical methods were compared in terms of postoperative anterior-posterior diameter there was no statistical difference.

Hidai et al. evaluated patients to whom hemilaminectomy decompression was applied and determined the mean spinal canal area as $169 \mathrm{~mm}^{2}$ (14). Ohsawa et al. reported the mean spinal canal area in patients that underwent laminoplasty as 144 
$\mathrm{mm}^{2}$ (14). Consistent with the literature, in our study the mean spinal canal area in patients that underwent hemilaminectomy was $161 \mathrm{~mm}^{2}$, while in patients that underwent laminoplasty it was $158 \mathrm{~mm}^{2}$. There was no statistically significant difference between the two surgical techniques in terms of postoperative spinal canal area.

Postoperative changes in the alignment of the cervical sagittal spine are important for the effectiveness of surgical procedures. Satomi et al. reported that after open door laminoplasty there is a decrease in cervical curvature index that is exacerbated from year to year (40). Hidai et al. reported a decrease in physiological cervical lordosis after bilateral laminoplasty (14). Moreover, Suk et al. conducted a prospective study and reported that the rate of development of kyphosis after laminoplasty was $10.6 \%$ (42). After the posterior cervical decompression procedure, preservation of lordotic structure and prevention of kyphosis are crucial. During the hemilaminectomy decompression procedure, protection of muscles attached to C2, preservation of the integrity of the nuchal ligament, and prevention of contact between interspinous and supraspinous ligaments and the contralateral paravertebral muscles contribute to maintaining the cervical sagittal alignment (14). In our study, during the postoperative follow-up in patients who underwent laminoplasty and hemilaminectomy, no changes were observed in the cervical sagittal alignment. In our opinion the fact that we did not observe any instabilities or changes in the sagittal alignment during the postoperative period might be because of preservation of ligament integrity and areas where erector spinae muscles were attached, which was similar to previously reported studies (28).

Hidai et al. evaluated postoperative sectional MRI images and reported seeing a profile consistent with cervical paravertebral muscular atrophy (14). For this reason, avoiding the disturbance of contralateral paravertebral muscles during the hemilaminectomy procedure is valuable in terms of preservation of cervical stabilization (14). In our study, postoperative MR images showed that contralateral paravertebral muscles were preserved after the hemilaminectomy procedure, while in the symptomatic areas where the surgical procedure was applied the development of muscle atrophy was observed. Moreover, in patients that underwent laminoplasty, bilateral paravertebral muscle atrophy was observed in the postoperative period.

With the introduction of MRI, detection of compressioninduced changes that occur in the spinal cord improved tremendously. In areas of the spinal cord where there is maximum compression, the changes in the MRI T2 hyperintense signal can be detected. Contrary to common belief, this situation is not only associated with myelomalacia. Hyperintense changes may be caused by one or more factors such as edema, ischemia, necrosis, and myelomalacia (29). The disappearance of hyperintense changes following the decompression procedure in some cases is the best proof of it. Whatever the reason, the area that has the hyperintense changes usually has the maximum compression. Hence, these particular regions should be decompressed (37). Mefty et al. reported that spinal cord MRI signal changes are compatible with pathological changes in the spinal cord (1). Meanwhile, Mehalic et al. suggested that high signal changes on T2-weighted sequences are nonspecific and might rather be indicative of edema, inflammation, vascular ischemia, gliosis, or myelomalacia (32). While many investigators have suggested that the high signal intensity on MRI T2-weighted sequences of the spinal cord is correlated with neurological status, others have not mentioned any clear correlation between them. Morio et al. reported that high signal intensity on T2-weighted sequences of the spinal cord in CSM patients might be a reflection of pathological changes, but it still cannot be used to predict the prognosis of CSM $(19,34,35,44)$. In our study, we did not detect any significant correlation between the observance of changes in the MRI T2-hyperintense and neurological improvement in patients who underwent hemilaminectomy and laminoplasty.

One of the frequent complaints after cervical laminoplasty and hemilaminectomy is axial neck pain. Pain localized in the shoulder and neck can be observed during the postoperative period. Hosono et al. reported the presence of axial pain symptoms after open door laminoplasty in $60 \%$ of the cases (18). Hidai et al. described the presence of axial symptoms in the area where decompression was done after the hemilaminectomy procedure (14). Kuwashima et al. reported low rates of axial pain in patients that underwent hemilaminectomy (25). In this study we evaluated axial pain by using the visual analogue scale. The mean VAS score in hemilaminectomy patients was $4.42 \pm 0.97$ while in laminoplasty patients it was $5.85 \pm 0.79$. The axial neck pain was significantly less in hemilaminectomy patients, compared to laminoplasty patients.

\section{- CONCLUSION}

Cervical spondylotic myelopathy is a progressive pathology that leads to deterioration of the patient's neurological status over time. With the introduction of new microsurgical instruments and increase in anatomical and physiological knowledge of this area, different methods for surgical treatment of CSM are being developed. Although in recent years, the open-door laminoplasty method came forward as the most commonly used method, in practice, complications associated with this method have been reported. We believe that cervical hemilaminectomy decompression method is an effective surgical treatment that can be used in CSM patients that have lordotic, straight, kyphotic or meandering sagittal alignment and that have narrowed spinal canal due to compression from the anterior or posterior, ossification of the posterior longitudinal ligament, calcified cervical disc herniation, osteophytic lesions and hypertrophic ligamentum flavum and other lesions, prominent myelopathic symptoms but no radicular symptoms. 


\section{REFERENCES}

1. Al-Mefty O, Harkey I: Experimental chronic compressive cervical myelopathy. J Neurosurgery 79: 550-561, 1993

2. Anderson PA, Matz PG, Groff MW, Heary RF, Holly LT, Kaiser MG, Mummaneni PV, Ryken TC, Choudhri TF, Vresilovic EJ, Resnick DK: Joint section on disorders of the spine and peripheral nerves of the American Association of Neurological Surgeons and Congress of Neurological Surgeons: Laminectomy and fusion for the treatment of cervical degenerative myelopathy. J Neurosurg Spine 11: 150-156, 2009

3. Baron EM, Young WF: Cervical spondylotic myelopathy. A brief review of its pathophysiology, clinical course and diagnosis. Neurosurgery 60: 35-41, 2007

4. Benzel EC, Lancon J, Kesterson L, Hadden T: Cervical laminectomy and dentate ligament section for cervical spondylotic myelopathy. J Spinal Disord 4: 286-295, 1991

5. Benzel EC: Biomechanics of Spine Stabilization. Illinois: Am Assoc of Neurol Surg, 2001

6. Benzel EC: The Cervical Spine, Philadelphia: Lippincott, Williams \& Wilkins, 2012: 51

7. Edwards WC, LaRocca H: The developmental segmental sagittal diameter of the cervical spinal canal in patients with cervical spondylosis. Spine 8: 20-27, 1983

8. Eser O, Koc RK: Servikal arkokristektomi. Türk Nöroşir Derg 19: 135-138, 2009 (In Turkish)

9. Fehlings MG, Arvin B: Surgical management of cervical degenerative disease: The evidence related to indications, impact and outcome. J Neurosurg Spine 11: 97-100, 2009

10. Fields MJ, Hoshijima K, Feng AH, Richardson WJ, Myers BS: A biomechanical radiologic, and clinical comparison of outcome after multilevel cervical laminectomy or laminoplasty in the rabbit. Spine 25: 2925-2931, 2000

11. Gocmez C, Koc RK, Tucer B, Menku A, Kurtsoy A: Prognostic factors in cervical spondylotic myelopathy: A clinical prospective study. Neurosurg Q 25: 34-40, 2015

12. Gulsen S, Yilmaz C, Ozdemir O: Servikal bölgede ön ve arka yaklaşım sonrası erken dönemde klinik değerlendirme ve servikal lordoz açısındaki değişim. Türk Nörosir Derg 19:2, 4149, 2009 (In Turkish)

13. Heller JG, Edwards C, Hideki M, Gerald E: Laminoplasty versus laminectomy and fusion for multilevel cervical myelopathy, an independent matched cohort analysis. Spine 26: 1330-1336, 2001

14. Hidai $Y$, Ebara S, Kamimura M, Tateiwa $Y$, Itoh H, Kinoshita T, Takaoka K, Ohtsuka K: Treatment of cervical compressive myelopathy with a new dorsolateral decompressive procedure. J Neurosurg (Spine 2) 90: 178-185, 1999

15. Hirabayashi K, Miyakawa J, Satomi K, Maruyama T, Wakano $\mathrm{K}$ : Operative results and postoperative progression of ossification among patients with ossification of cervical posterior longitudinal ligament. Spine 6: 354-364, 1981

16. Hirabayashi S, Yamada H, Motosuneya T, Watanabe $Y$, Miura M, Sakai H, Matsushita T: Comparison of enlargement of the spinal canal after cervical laminoplasty: Open-door type and double-door type. Eur Spine J 19: 1690-1694, 2010
17. Hirai T, Okawa A, Arai Y, Takahashi M, Kawabata S, Kato T, Enomoto M, Tomizawa S, Sakai K, Torigoe I, Shinomiya K: Middle-term results of a prospective comparative study of anterior decompression with fusion and posterior decompression with laminoplasty for the treatment of cervical spondylotic myelopathy. Spine 36: 1940-1947, 2011

18. Hosono N, Sakaura H, Mukai Y, Yoshikawa H: The source of axial pain after cervical laminoplasty-C7 is more crucial than deep extensor muscles. Spine 32: 2985-2988, 2007

19. Jun JS, Jin BH, Kim KS, Cho YE, Cho WH: Intramedullary high signal intensity and neuorological status as prognostic factors in cervical spondylotic myelopathy. Acta Neurochir 152: 16871694, 2010

20. Kaner T, Sasani M, Oktenoglu T, Ozer AF: Clinical outcomes following cervical laminoplasty for 19 patients with cervical spondylotic myelopathy. Turk Neurosurg 19: 121-126, 2009

21. Karadimas SK, Gatzounis G, Fehlings MG: Pathobiology of cervical spondylotic myelopathy. Eur Spine J 24 Suppl 2:132138, 2015

22. King JR, Moossy JJ, Tsevat J, Roberts MS: Multimodal assessment after surgery for cervical spondylotic myelopathy. J Neurosurg Spine 2: 526-534, 2005

23. Koc RK: Servikal Dejeneratif Disk Hastalığı ve Üst Ekstremite Tuzak Nöropatileri. 1. Baskı. Ankara: Türk Nöroşirürji Derneği, 2009: 223-226 (In Turkish)

24. Krita Y: Posterior decompression for cervical spondylosis and OPLL. Shujutsu 30: 287-302, 1976 (In Japanese)

25. Kuwashima U, Tsuchiya $\mathrm{K}, \mathrm{Y}$ Hidehiko, Tomishige $\mathrm{O}$, Sakamoto $\mathrm{H}$, Kawamura $\mathrm{H}$ : Short-term results and problems of hemilaminectomy for cervical spondylotic myelopathy. Orthop Trauma 59: 872-874, 2010

26. Lao L, Zhong G, Li X, Qian L, Liu Z: Laminoplasty versus laminectomy for multi-level cervical spondylotic myelopathy: A systematic review of the literature. J Orthop Surg Res 8: 45,2013

27. Lee TT, Manzano GR: Modified open-door cervical expansive laminoplasty for spondylotic myelopathy, operative technique, outcome and predictors for gait improvement. J Neurosurg 86: 64-68, 1997

28. Liu J, Ebraheim NA, Sanford CG, Patil V, Haman SP, Ren $\mathrm{L}$, Yang $\mathrm{H}$ : Preservation of the spinous process-ligamentmusclecomplex to prevent kyphotic deformity following laminoplasty. Spine J 7: 159-164, 2007

29. Machino M, Yukawa Y, Ito K, Nakashima H, Kato F: Dynamic changes in dural sac and spinal cord cross-sectional area in patients with cervical spondylotic myelopathy. Spine 36: 399403, 2011

30. Matsuyama Y, Kawakami N, Mimatsu K: Spinal cord expansion after decompression in cervical myelopathy, investigation by computed tomography myelography and ultrasonography. Spine 20: 1657-1663, 1995

31. McAllister BD, Rebholz BJ, Wang CJ: Is posterior fusion necessary with laminectomy in the cervical spine? Surg Neurol Int 3: 225-231, 2012

32. Mehalic TF, Pezzuti RT, Applebaum BI: Magnetic resonance imaging and cervical spondylotic myelopathy. Neurosurgery 26: 217-227, 1990 
33. Minamide A,Yoshida M, Yamada H, Nakagawa $Y$, Maio K, Kawai M, Iwasaki $\mathrm{H}$ : Clinical outcomes of microendoscopic decompression surgery for cervical myelopathy. Euro Spine J 19: 487-493, 2010

34. Morio Y, Teshima R, Nagashima H, Nawata K, Yamasaki D, Nanjo Y: Correlation between operative outcomes of myelopathy and MRI of the spinal cord. Spine 26:1238-1245, 2001

35. Morio Y, Yamamoto K, Kuranobu K, Murata M, Tuda K: Does increased signal intensity of the spinal cord on MR images due to cervical myelopathy predict prognosis? Arch Orthop Trauma Surg 113: 254-259, 1994

36. Naderi S, Ozgen S, Pamir NM, Ozek M, Erzen C: Cervical spondylotic myelopathy; surgical result and factors affecting prognosis. Neurosurgery 43:43-49, 1998

37. Naderi S: Servikal spondilotik miyelopatide cerrahi yaklaşım seçimi. Türk Nöroşir Derg 10: 137 -143, 2000 (In Turkish)

38. Petraglia A, Srinivasan V, Coriddi M, Gordon MW, Maxwell JT, Silberstein $\mathrm{HJ}$ : Cervical laminoplasty as a management option for patients with cervical spondylotic myelopathy: A Series of 40 Patients. Neurosurgery 67: 272-277, 2010

39. Sakaura H, Hosono N, Mukai Y, Ishii T, Iwasaki M, Yoshikawa $\mathrm{H}$ : Long-term outcome of laminoplasty for cervical myelopathy due to disc herniation: A comparative study of laminoplasty and anterior spinal fusion. Spine 30: 756-759, 2005

40. Satomi K, Nishu Y, Kohno T, Hirabayashi K: Long-term followup studies of open-door expansive laminoplasty for cervical stenotic myelopathy. Spine 19: 507-510, 1994
41. Shin J, Steinmetz M, Benzel EC, Krishnaney A: Dorsal versus ventral surgery for cervical ossification of the posterior longitudinal ligament, considerations for approach selection and review of surgical outcomes. Neurosurg Focus 30: 3-8, 2011

42. Suk KS, Kim KT, Lee JH, Lee SH, Lim YJ, Kim JS: Sagittal alignment of the cervical spine after the laminoplasty. Spine 32: 656-660, 2007

43. Uchida K, Nakajima H, Sato R, Yayama T, Mwaka ES, Kobayashi S, Baba H: Cervical spondylotic myelopathy associated with kyphosis or sagittal sigmoid alignment; outcome after anterior or posterior decompression. J Neurosurg Spine 11: 521-528, 2009

44. Wada E, Yonenobu K, Suzuki S, Kanazawa A, Ochi T: Can intramedullary signal change on magnetic resonance imaging predict surgical outcome in cervical spondylotic myelopathy? Spine 24: 455-461, 1999

45. Wang MY, Shah S: Clinical outcomes following cervical laminoplasty for 204 patients with cervical spondylotic myelopathy. Surg Neurol 62: 487-493, 2004

46. Wewers ME, Lowe NK: A critical review of visual analogue scales in the measurement of clinical phenomena. Res in Nurs \& Health 13: 227-236, 1990

47. Yamazaki T, Yanaka K, Sato H: Cervical Spondylotic Myelopathy, surgical results and factors affecting outcome with special reference to age differences. Neurosurgery 52: 122-126, 2003

48. Zhang Z, Wang $\mathrm{H}$ : Is the "snake-eye" MRI sign correlated to anterior spinal artery occlusion on CT angiography in cervical spondylotic myelopathy and amyotrophy? Eur Spine J 23: 1541-1547, 2014 